\title{
HìNH ẢNH CỘNG HƯỞNG TƯ' TỔN THƯƠNG ĐÁM RỐI THẦN KINH CÁNH TAY SẢN KHOA Ở TRẺ EM
}

\author{
Ngô Văn Đoan ${ }^{1, \bigotimes}$, Bùi Văn Giang ${ }^{2}$, Nguyễn Hồng Hà ${ }^{3}$ \\ ${ }^{1}$ Bệnh viện Đa khoa Quốc tế Vinmec Times City \\ ²Bệnh viện $K$. \\ ${ }^{3} B$ ệnh viện Việt Đức
}

Chấn thương đám rối thần kinh cánh tay sản khoa không hiếm gặp. Chẩn đoán bệnh trước đây phụ thuộc vào khám lâm sàng và điện cơ kim. Cộng hưởng từ 3 Tesla ( $\mathrm{CHT} 3 T$ ) đám rối thần kinh cánh tay là phương pháp chẩn đoán mới được áp dụng gần đây trong chẩn đoán bệnh đám rối thần kinh cánh tay, đặc biệt là ở trẻ em. Mục tiêu của nghiên cứu nhằm đánh giá hiệu quả của $3 T$ MRI trong việc chẩn đoán đám rối thần kinh cánh tay. Nghiên cứu trên 75 bệnh nhi được chụp CHT $3 T$ cho thấy: toàn bộ các đám rối thần kinh cánh tay đều được hiện ảnh với chất lượng tốt $(3,1 \pm 0,25$ điểm trên $T 1 W$ và $3,9 \pm 0,11$ điểm trên $T 2 W$, STIR và CISS); tất cả các rễ $C 5, C 6$ đều bị tổn thương, trong đó ưu thế là tổn thương độ $I V$ và độ $V$; các rễ $C 7, C 8$ tỉ lệ gặp tổn thương thấp hơn nhưng phần lớn là độ $V$; trong các rễ bệnh lý tỉ lệ nhổ rễ 34\%, giả thoát vị màng tủy 32,3\%, u xơ thần kinh 40,2\%, phù nề rễ 94,8\%.Tóm lại CHT $3 T$ là phương pháp chẩn đoán không xâm nhập, giúp đánh giá và phân loại tổn thương đám rối thần kinh cánh tay ở trẻ em nhằm tiên lượng và lập kế hoạch điều trị bệnh.

Từ khóa. tổn thương đám rối thần kinh sản khoa, cộng hưởng từ 3Tesla, liệt Erb.

\section{I. ĐẠT VẤN ĐÊ}

Chấn thương đám rối thần kinh cánh tay sản khoa gặp với tỉ lệ 0,5 tới 3 trường hợp trên mỗi 1000 ca sinh. ${ }^{1}$ Nghiên cứu của Lalka và cs (2020) trên 966.447 trẻ sơ sinh cho thấy tổn thương này liên quan tới nhiều yếu tố nguy cơ khác nhau song quan trọng nhất là kẹt vai khi sinh và thai to. ${ }^{2}$ Phân tích gộp và tổng quan hệ thống của Van der Looven và cs (2020) trên 24 nghiên cứu với tổng cỡ mẫu trên 29 triệu trẻ sơ sinh cho kết quả tỉ lệ mắc là 1,74/1000 trẻ, trong đó kẹt vai và thai to là hai yếu tố nguy cơ hàng đầu của đám rối thần kinh cánh tay ở nhóm đối tượng này. ${ }^{3}$

Các nghiên cứu cho thấy tiến triển lâm sàng tổn thương đám rối thần kinh cánh tay sản khoa

Tác giả liên hệ: Ngô Văn Đoan,

Bệnh viện Đa khoa Quốc tế Vinmec

Email: doanxr2013@gmail.com

Ngày nhận: 20/10/2020

Ngày được chấp nhận: 10/11/2020 rất thay đổi và nằm giữa hai thái cực: một mặt phần lớn bệnh nhân có khả năng phục hồi chức năng chi hoàn toàn trong tháng đầu tiên sau đẻ mà không cần can thiệp, song mặt khác tỉ lệ tàn tật vĩnh viễn ở các bệnh nhân còn lại có thể lên tới 18 - 23\% nếu không được chẩn đoán và điều trị sớm. ${ }^{4-6}$

Trước đây chẩn đoán sớm bệnh đám rối thần kinh cánh tay sau sinh phụ thuộc chủ yếu vào thăm khám lâm sàng, điện cơ kim và theo dõi, tuy nhiên cách tiếp cận này đôi khi làm chậm quá trình chẩn đoán và phân loại tổn thương dẫn tới can thiệp muộn ở thời điểm các thương tổn thần kinh mất khả năng hồi phục. ${ }^{1}$ Trong những năm gần đây, chụp CHT $3 T$ đám rối thần kinh cánh tay đã được ứng dụng trong thực hành lâm sàng như một giải pháp chẩn đoán mới cung cấp hình ảnh trực quan của đám rối thần kinh cánh tay, giúp phát hiện sớm và phân loại tổn thương để có hướng xử trí sớm và phù hợp. So sánh với các thế hệ máy 
với từ lực thấp hơn, hình ảnh $\mathrm{CHT} 3 \mathrm{~T}$ có chỉ số nhiễu SNR thấp hơn nhiều lần, do đó làm tăng độ phân giải chi tiết của hình ảnh và giảm thời gian chụp, phù hợp cho ứng dụng với trẻ em, là đối tượng có kích thước đám rối thần kinh cánh tay nhỏ. ${ }^{7}$ Tuy nhiên các nghiên cứu về hình ảnh tổn thương đám rối thần kinh cánh tay sản khoa trên $\mathrm{CHT}$ nói chung và $\mathrm{CHT} 3 \mathrm{~T}$ hiện chưa nhiều, đặc biệt là ở các nước đang phát triển. Do đó nghiên cứu này được thực hiện với mục đích mô tả đặc điểm hình ảnh và phân loại tổn thương đám rối thần kinh cánh tay sản khoa ở trẻ em được chụp CHT 3T đám rối thần kinh cánh tay.

\section{II. ĐỐI TƯỢNG VÀ PHƯƠNG PHÁP}

\section{1. Đối tượng}

75 bệnh nhân được chẩn đoán tổn thương đám rối thần kinh cánh tay trên lâm sàng, phân loại tổn thương theo phân loại Narakas, được chỉ định chụp $\mathrm{CHT} 3 \mathrm{~T}$ đám rối thần kinh cánh tay để xác định và phân loại tổn thương xét phẫu thuật.

\section{Phương pháp}

Nghiên cứu mô tả chùm bệnh trên 75 bệnh nhân, gồm toàn bộ các trường hợp được chẩn đoán tổn thương đám rối thần kinh cánh tay sản khoa trên lâm sàng, được chụp $\mathrm{CHT} 3 \mathrm{~T}$ tại BV đa khoa quốc tế Vinmec từ 09/2016 đến 03/2020, Toàn bộ phim chụp được đọc bởi một bác sĩ chẩn đoán hình ảnh để đảm bảo tính đồng nhất của kết quả.

Các chuỗi xung được sử dụng trong nghiên cứu bao gồm. Coronal 2D - T1W (FOV 300 mm, độ dày lát cắt $4 \mathrm{~mm}$, TR/TE 880/11, ma trận 512 x 512), Coronal 3D - STIR (FOV $300 \mathrm{~mm}$, độ dày lát cắt $0,5-1 \mathrm{~mm}$, TR/TE 3000/198, ma trận 320 x 384), Sagittal 2D - T2W (FOV 300 $\mathrm{mm}$, độ dày lát cắt $3 \mathrm{~mm}, \mathrm{TR} / \mathrm{TE} 3700 / 85$, ma trận $320 \times$ 384), Coronal CISS (FOV 200 mm, độ dày lát cắt 2 mm, TR/TE 8,5/4, ma trận 320 $x$ 384) và Axial CISS (FOV 300 mm, độ dày lát cắt 2,5 mm, TR/TE 9/4, ma trận 320 x 384).

Chất lượng hình ảnh được đánh giá trên 4 chuỗi xung 2D - T1W, 2D - T2W, STIR và CISS (3D - T2W) dựa trên thang điểm 4 bậc theo phương pháp Linkert (1đ. Không đánh giá được cấu trúc thần kinh ; 2đ. Quan sát được dây thần kinh nhưng không đánh giá được tổn thương ; 3đ. Quan sát và đánh giá được một phần tổn thương thần kinh ; 4đ :Hiện ảnh rõ và đánh giá được toàn bộ các dây thần kinh)

Đánh giá mức độ nặng của tổn thương rễ thần kinh trên hình ảnh dựa theo phân độ Sunderland (Bảng 1). Phân loại vị trí tổn thương theo tương quan với hạch thần kinh tủy sống gồm tổn thương trước hạch, sau hạch hoặc cả hai.

\section{Bảng 1. Phân độ tổn thương rễ thần kinh theo Sunderland và đặc điểm hình ảnh $\mathrm{CHT}$ tương ứng ${ }^{9}$}

\section{Tổn thương thần kinh}

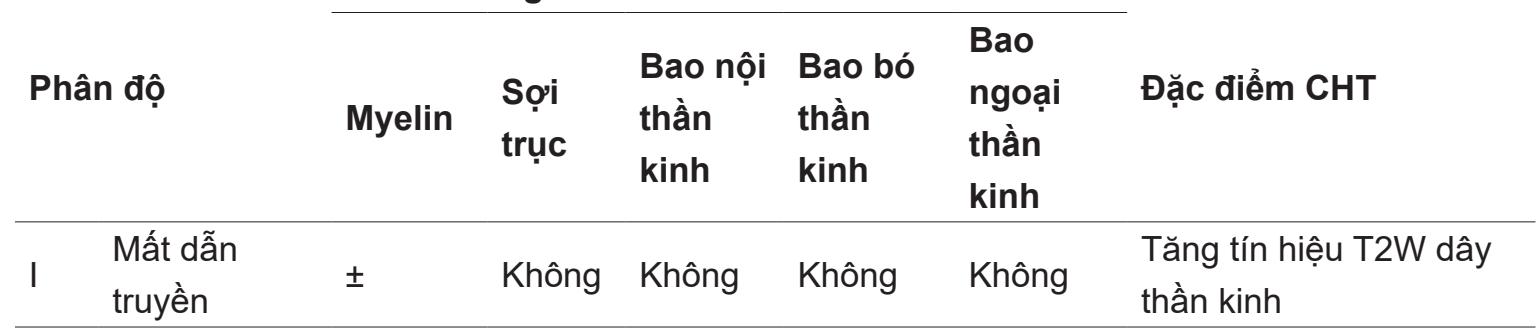




\section{Tổn thương thần kinh}

\begin{tabular}{|c|c|c|c|c|c|c|c|}
\hline \multicolumn{2}{|c|}{ Phân độ } & Myelin & $\begin{array}{l}\text { Sợi } \\
\text { trục }\end{array}$ & $\begin{array}{l}\text { Bao nội } \\
\text { thần } \\
\text { kinh }\end{array}$ & $\begin{array}{l}\text { Bao bó } \\
\text { thần } \\
\text { kinh }\end{array}$ & $\begin{array}{l}\text { Bao } \\
\text { ngoại } \\
\text { thần } \\
\text { kinh }\end{array}$ & Đặc điểm CHT \\
\hline II & Đứt sợi trục & Có & Có & Không & Không & Không & $\begin{array}{l}\text { - Phì đại và tăng tín } \\
\text { hiệu T2W lan tỏa dây } \\
\text { thần kinh } \\
\text { - Vỏ bao thần kinh bình } \\
\text { thường }\end{array}$ \\
\hline III & & Có & Có & Có & Không & Không & $\begin{array}{l}\text { - Phì đại và tăng tín } \\
\text { hiệu T2W lan tỏa dây } \\
\text { thần kinh } \\
\text { - Vỏ bó thần kinh có thể } \\
\text { dày hoặc méo do phù }\end{array}$ \\
\hline IV & $\begin{array}{l}\text { U xơ thần } \\
\text { kinh , liên tục }\end{array}$ & Có & Có & Có & Có & Không & $\begin{array}{l}\text { - Phì đại khu trú kèm } \\
\text { biến đổi tín hiệu lan tỏa, } \\
\text { không đều dây thần kinh } \\
\text { - Có thể kèm theo mất } \\
\text { liên tục vỏ bó }\end{array}$ \\
\hline V & $\begin{array}{l}\text { Đứt hoàn } \\
\text { toàn dây } \\
\text { thần kinh }\end{array}$ & Có & Có & Có & Có & Có & $\begin{array}{l}\text { Mất liên tục hoàn toàn } \\
\text { dây thần kinh } \pm \text { máu tụ } \\
\text { và xơ hóa trong khu vực } \\
\text { thần kinh gián đoạn. } \\
\text { Dày bao ngoại thần kinh }\end{array}$ \\
\hline
\end{tabular}

Thống kê tỉ lệ xuất hiện của các tổn thương: nhổ rễ con (rễ trước, rễ sau hoặc cả hai), đứt rời rễ sau hạch, u xơ thần kinh, giả thoát vị màng cứng, phù nề lan tỏa rễ thần kinh và xơ hóa phần mềm quanh rễ thần kinh.

\section{3. Đạo đức nghiên cứu}

Bài báo này là một phần kết quả thuộc đề tài « Nghiên cứu đặc điểm hình ảnh và giá trị của CHT $3 T$ trong chẩn đoán tổn thương đám rối thần kinh cánh tay ở trẻ em do chấn thương sản khoa» đã được Hội đồng Đạo đức trong nghiên cứu Y sinh học Đại học Y Hà Nội (IRB00003121) thông qua ngày 06 tháng 01 năm 2017, theo quyết định số 22/HĐĐĐĐHYHN.

Các bệnh nhân trong nghiên cứu được chỉ định chụp $\mathrm{CHT} 3 \mathrm{~T}$ đám rối thần kinh cánh tay nhằm mục đích đánh giá mức độ tổn thương để phục vụ điều trị vì lợi ích của người bệnh. Bệnh nhân/người giám hộ bệnh nhân được giải thích kỹ càng về mục đích của nghiên cứu, đồng ý và ký cam kết tham gia nghiên cứu.

\section{KÉT QUẢ}

\section{1. Đặc điểm chung}

Số lượng bệnh nhân nữ chiếm ưu thế với tỉ lệ nữ :nam là $1,2: 1$, chủ yếu là bệnh nhân nhỏ $\leq 1$ tuổi, hầu hết có cân nặng cao khi sinh với cân nặng trung bình và số trung vị rất sát nhau, xấp xỉ 3900 gram. Liệt tay phải gặp nhiều hơn liệt tay trái. Tỉ lệ bệnh nhân nặng Narakas 3 và Narakas 4 rất cao, với tổng tỉ lệ $56 \%$. 


\section{Bảng 2. Đặc điểm lâm sàng nhóm bệnh nhân trong nghiên cứu}

\begin{tabular}{|c|c|}
\hline \multicolumn{2}{|l|}{ Giới (n = 75) } \\
\hline$-\operatorname{Nam}(n=34)$ & $45,3 \%$ \\
\hline - Nữ $(n=41)$ & $54,7 \%$ \\
\hline \multicolumn{2}{|l|}{ Tuổi (n = 75) } \\
\hline - Trung bình \pm Sd & 7,2 $\pm 5,30$ (tháng) \\
\hline - Min & 0 ( < 1 tháng tuổi) \\
\hline- Max & 108 (tháng) \\
\hline - $\leq 12$ tháng $(n=68)$ & $90,7 \%$ \\
\hline - > 12 tháng $(n=7)$ & $9,3 \%$ \\
\hline \multicolumn{2}{|l|}{ Cân nặng khi sinh } \\
\hline - Trung bình \pm Sd (min, max) & $3910,7 \pm 493,08$ (gram) \\
\hline - Trung vị & 3900 (gram) \\
\hline - Mode & 3800 (gram) \\
\hline \multicolumn{2}{|l|}{ Chi liệt } \\
\hline - Liệt tay phải (n = 49) & $65,3 \%$ \\
\hline - Liệt tay trái (n = 26) & $34,7 \%$ \\
\hline \multicolumn{2}{|l|}{ Phân độ tổn thương trên lâm sàng } \\
\hline - Narakas 1 (liệt Erb cao) (n = 10) & $13,3 \%$ \\
\hline - Narakas 2 (liệt Erb lan rộng) (n = 23) & $30,7 \%$ \\
\hline - Narakas 3 (liệt hoàn toàn không kèm hội chứng Horner) $(n=22)$ & $29,3 \%$ \\
\hline - Narakas 4 (liệt hoàn toàn kèm hội chứng Horner) (n = 20) & $26,7 \%$ \\
\hline
\end{tabular}

\section{2. Đặc điểm hình ảnh}

Toàn bộ 75 đám rối và 375 rễ thần kinh đều được hiện ảnh với chất lượng tốt trên phim chụp $\mathrm{CHT}$ $3 T$, với điểm số trung bình theo bậc thang 4 điểm của chuỗi xung $2 \mathrm{D}$ - T1W là 3,1 0 ,25 so với 3,9 $\pm 0,11$ của các các chuỗi xung 2D - T2W, STIR và CISS.

Về phân bố tổn thương, toàn bộ các rễ C5 và C6 đều bị tổn thương ở các mức độ khác nhau, trong đó tổn thương nặng chiếm ưu thế với tổng tỉ lệ các tổn thương độ IV và độ V lần lượt là $56 \%$ ở nhóm rễ C5 và $61,4 \%$ ở nhóm rễ C6. Tỉ lệ rễ C7 tổn thương cũng rất cao lên tới 89,3\% trong đó có tới hơn một nửa là tổn thương độ V. Các rễ C8 và T1 có nguy cơ tổn thương thấp hơn, số lượng rễ bình thường lần lượt là $42,7 \%$ ở nhóm rễ C8 và $60 \%$ ở nhóm rễ T1 tuy nhiên ở các rễ này nếu bị tổn thương thì hầu hết đều là tổn thương độ $\mathrm{V}$ (Bảng 3 ).

Bảng 3. Phân bố mức độ tổn thương của các rễ thần kinh trong nghiên cứu

\begin{tabular}{lccccc}
\hline & \multicolumn{5}{c}{ Mức độ tổn thương theo Sunderland } \\
\cline { 2 - 6 } & Bình thường & Độ I & Độ II - III & Độ IV & Độ V \\
\hline C5 (n=75) & $0 \%$ & $2,7 \%$ & $41,3 \%$ & $17,3 \%$ & $38,7 \%$ \\
\hline
\end{tabular}




\begin{tabular}{lccccc}
\hline & \multicolumn{5}{c}{ Mức độ tổn thương theo Sunderland } \\
\cline { 2 - 6 } & Bình thưò̀ng & Độ I & Độ II - III & Độ IV & Độ V \\
\hline C6 $(n=75)$ & $0 \%$ & $1,3 \%$ & $37,3 \%$ & $18,7 \%$ & $42,7 \%$ \\
\hline C7 $(n=75)$ & $10,7 \%$ & $1,3 \%$ & $26,7 \%$ & $4,0 \%$ & $57,3 \%$ \\
\hline C8 $(n=75)$ & $42,7 \%$ & $2,7 \%$ & $2,7 \%$ & $4,0 \%$ & $48 \%$ \\
\hline T1 $(n=75)$ & $60 \%$ & $9,3 \%$ & $2,7 \%$ & $1,3 \%$ & $26,7 \%$
\end{tabular}

Về vị trí tổn thương, các rễ cổ cao $\mathrm{C} 5, \mathrm{C} 6$ hay gặp tổn thương sau hạch trong khi các rễ cổ thấp tổn thương trước hạch thường gặp hơn (Bảng 4).

Bảng 4. Phân bố vị trí tổn thương của các rễ thần kinh trong nghiên cứu

\begin{tabular}{lccc}
\hline & \multicolumn{3}{c}{ Vị trí tổn thương } \\
\cline { 2 - 4 } & Trước hạch & Sau hạch & Hỗn hợp \\
\hline C5 $(n=75)$ & $5,3 \%$ & $90,4 \%$ & $1,3 \%$ \\
\hline C6 $(n=75)$ & $17,3 \%$ & $82,7 \%$ & $0 \%$ \\
\hline C7 $(n=68)$ & $43,3 \%$ & $55,2 \%$ & $1,5 \%$ \\
\hline C8 $(n=43)$ & $74,4 \%$ & $23,3 \%$ & $2,3 \%$ \\
\hline T1 $(n=30)$ & $63,3 \%$ & $36,7 \%$ & $0 \%$ \\
\hline
\end{tabular}

Trong số 375 rễ thần kinh được thăm khám có 291 rễ bệnh lý, tỉ lệ xuất hiện của các dấu hiệu hình ảnh trên những rễ này được trình bày trong Bảng 5 .

Bảng 5. Tỉ lệ xuất hiện của một số dấu hiệu hình ảnh trên các rễ bệnh lý

\section{Nhổ rễ}

Không có nhổ rễ

Nhổ rễ trước

Nhổ rễ sau

Nhổ cả hai rễ

\section{Giả thoát vị màng tủy}

Không có

Có, kết hợp nhổ rễ

Có, không kết hợp nhổ rễ

\section{$\mathrm{U}$ xơ thần kinh}

Không có

Có

\section{Phù nề rễ thần kinh}

Không có

Có

\section{BÀN LUẦN}

Ứng dụng $\mathrm{CHT}$ trong đánh giá đám rối thần kinh cánh tay đã được đề cập và ứng dụng trên lâm

$$
\begin{gathered}
192(66,0 \%) \\
6(2,1 \%) \\
3(1 \%) \\
90(30,9 \%)
\end{gathered}
$$

$$
\begin{gathered}
197(67,7 \%) \\
91(31,3 \%) \\
3(1 \%)
\end{gathered}
$$

$174(59,8 \%)$

$117(40,2 \%)$

$$
\begin{gathered}
15(5,2 \%) \\
276(94.8 \%)
\end{gathered}
$$


sàng từ lâu nhưng chủ yếu là cho người trưởng thành. Đối với trẻ em do kích thước đám rối nhỏ nên thế hệ máy $\mathrm{CHT}$ có từ lực từ 1,5 Tesla trở về trước có vai trò rất hạn chế. Một số nghiên cứu gần đây cho thấy $\mathrm{CHT} 3 \mathrm{~T}$ có khả năng tạo ảnh đám rối thần kinh cánh tay với mức độ chi tiết hơn cũng như giúp giảm nhiễu ảnh và thời gian chụp, do đó có tiềm năng ứng dụng cho trẻ em. ${ }^{7}$ Kết quả nghiên cứu của chúng tôi cho thấy CHT 3T giúp đánh giá được toàn bộ các đám rối thần kinh cánh tay của bệnh nhân nghiên cứu, trong đó các xung bản chất T2W (2D - T2W, 3D - STIR, CISS) có khả năng tạo ảnh với độ chi tiết cao hơn so với xung T1W. Trên thực tế các chuỗi xung này là các chuỗi xung được sử dụng chính trong đánh giá tổn thương đám rối.

Theo kinh nghiệm của chúng tôi, khảo sát hình ảnh đám rối thần kinh cánh tay ở trẻ em nên bắt đầu với chuỗi xung Coronal $\mathrm{T} 1 \mathrm{~W}$ để đánh giá sơ bộ hình ảnh gãy xương, các mốc giải phẫu, tổn thương teo cơ để khoanh vùng tổn thương. Tiếp đến là quan sát trên chuỗi xung Coronal 3D - STIR so sánh đám rối thần kinh cánh tay hai bên để phát hiện các rễ thần kinh tổn thương. Chuỗi xung Sagittal 2D - T2W được dùng để xác định vị trí tổn thương của đám rối. Cuối cùng sử dụng chuỗi xung Coronal CISS và Axial CISS để đánh giá các rễ con nối với cột tủy, ổ giả thoát vị màng não tủy, tổn thương tủy nếu có. Trong trường hợp không có bệnh lý, tín hiệu của các dây thần kinh, lớp mỡ xung quanh cũng như các cơ sẽ đồng nhất.

Tổn thương đám rối thần kinh cánh tay có nhiều mức độ khác nhau, từ mất myelin, mất sợi trục, phối hợp cả hai dạng tổn thương cho tới đứt rời toàn bộ dây thần kinh. Trên thực tế lâm sàng, ở trẻ có tổn thương đám rối thần kinh cánh tay, tổn thương thường không khu trú tại một vị trí mà thường ảnh hưởng tới nhiều vùng của dây thần kinh cũng như tổn thương cùng lúc nhiều dây thần kinh với các mức độ thương tổn khác nhau. Chỉ định điều trị phẫu thuật hay không, lựa chọn phẫu thuật nào sẽ phụ thuộc vào mức độ nặng của tổn thương, dây thần kinh bị ảnh hưởng và khả năng hồi phục của dạng thương tổn.

Phân độ Sunderland (1951) là phân độ kinh điển được các nhà phẫu thuật thần kinh áp dụng rộng rãi trong lựa chọn bệnh nhân phẫu thuật và tiên lượng bệnh. Theo đó các tổn thương từ độ III trở xuống (bao bó và bao ngoại thần kinh còn liên tục) sẽ được chỉ định điều trị nội khoa và theo dõi, các tổn thương độ IV trở lên (tạo u xơ thần kinh hoặc đứt rời thần kinh) là các tổn thương không có khả năng tự hồi phục sẽ được điều trị phẫu thuật. ${ }^{8}$ Đặc điểm tín hiệu của đám rối thần kinh cánh tay trên $\mathrm{CHT}$ cũng phản ánh các tổn thương vi thể tương ứng, ${ }^{9}$ đặc biệt là các tổn thương sau hạch.

Trên hình ảnh $\mathrm{CHT}$, các tổn thương độ I thường chỉ có dấu hiệu tăng tín hiệu đơn thuần trên T2W, gây ra bởi tình trạng phù nề do tổn thương các cấu trúc mạch máu của bao nội thần kinh. Tương tự các tổn thương độ II và III cũng gây tăng tín hiệu lan tỏa trên T2W, có thể quan sát thấy hình ảnh méo mó của vỏ bao thần kinh song tín hiệu dây thần kinh còn đồng nhất. Do độ phân giải của $\mathrm{CHT}$ hiện nay không đủ để hiện ảnh chi tiết các cấu trúc bao nội và bao bó thần kinh nên việc phân biệt tổn thương độ II và độ III qua các dấu hiệu trực tiếp trên CHT là không khả thi. Tuy nhiên trên khía cạnh lâm sàng, việc phân biệt này không mang nhiều ý nghĩa, do cả hai đều được điều trị nội khoa bảo tồn và phục hồi chức năng. Tổn thương độ IV là tổn thương tạo $\mathrm{u}$ xơ thần kinh liên tục, biểu hiện trên hình ảnh $\mathrm{CHT}$ là một ổ phì đại khu trú trên đường đi của rễ thần kinh với tín hiệu không đồng nhất do cấu trúc hỗn hợp của tổn thương (gồm cả đầu mút thần kinh, tổ chức xơ và giáng chất của máu). Hình ảnh tín hiệu không đồng nhất rất quan trọng để phân biệt 
giữa tổn thương giai đoạn III và IV. Tổn thương độ $\mathrm{V}$ là tổn thương gây đứt rời hoàn toàn dây thần kinh, do đó có thể quan sát thấy trên hình ảnh những khoảng trống giữa các đầu mút thần kinh. Khi gặp dạng tổn thương này cần lưu ý đo khoảng cách giữa hai đầu mút thần kinh để lựa chọn giải pháp phẫu thuật.

Hai kỹ thuật mổ được áp dụng trong điều trị bệnh lý đám rối thần kinh cánh tay là phẫu thuật nối thần kinh hoặc chuyển đoạn thần kinh (trong hoặc ngoài đám rối). Việc lựa chọn kỹ thuật nào hoặc phối hợp cả hai kỹ thuật sẽ phụ thuộc vào tương quan giữa vị trí tổn thương và hạch thần kinh tủy sống. ${ }^{10}$ Với các tổn thương trước hạch, chủ yếu là do nhổ rễ (một hoặc cả hai rễ con) tương đương với mất liên kết với hệ thần kinh trung ương do đó việc phẫu thuật nối thần kinh vào các rễ tổn thương không có tác dụng. Đối với tổn thương sau hạch, do vẫn còn liên kết giữa các rễ thần kinh với hệ thần kinh trung ương nên các rễ này vẫn có thể sử dụng để nối thần kinh.

Trên $\mathrm{CHT}$, hình ảnh ổ giả thoát vị màng não tủy là dấu hiệu chẩn đoán tổn thương trước hạch và thường đi kèm với tổn thương nhổ rễ của đám rối. Mặc dù vậy chỉ có khoảng $80 \%$ số trường hợp nhổ rễ có kèm theo ổ giả thoát vị màng não tủy. Một số tác giả cũng báo cáo về những trường hợp có hình ổ giả thoát vị màng não tủy nhưng không có tổn thương nhổ rễ. ${ }^{11}$

Nhổ rễ trong tổn thương đám rối thần kinh cánh tay do chấn thương thường gây đứt hoàn toàn cả hai rễ trước và sau. Tỉ lệ đứt đơn độc một rễ hiếm gặp hơn, chỉ từ 4,5 - 5,5\% theo y văn. ${ }^{12,13}$ Chẩn đoán nhổ rễ trên $\mathrm{CHT}$ dựa vào dấu hiệu mất liên tục trực tiếp của rễ thần kinh hoặc không quan sát thấy rễ thần kinh bám vào cột tủy. Ngoài ra có thể dựa vào một số dấu hiệu hình ảnh khác như di lệch của cột tủy về bên lành, dấu hiệu phù tủy của cột tủy cổ cạnh chỗ bám của rễ hoặc các biến đổi tín hiệu của cơ cạnh sống. ${ }^{14}$ song trong một số trường hợp rễ thần kinh có thể bị co lại và không quan sát được.

Đối với bệnh lý đám rối thần kinh cánh tay ở trẻ em, điểm then chốt trong quản lý và điều trị là cần phát hiện sớm cũng như tiên lượng được tiến triển của bệnh để ra quyết định phẫu thuật kịp thời, khi mà các tổn thương thần kinh còn khả năng hồi phục. ${ }^{1}$ Với cách tiếp cận trước đây sử dụng lâm sàng và điện cơ đơn thuần do không đánh giá được chính xác vị trí tổn thương nên có thể bỏ lỡ cơ hội vàng trong điều trị phẫu thuật của bệnh nhi, làm hạn chế khả năng phục hồi. Việc sử dụng kết hợp $\mathrm{CHT}$ trong chẩn đoán có thể mang lại nhiều giá trị không chỉ trong chẩn đoán mà còn cả về khả năng tiên lượng, ảnh hưởng tới quyết định phẫu thuật trong nhiều trường hợp..$^{15}$

\section{KÉT LUẦN}

Sử dụng $\mathrm{CHT} 3 \mathrm{~T}$ trong chụp đám rối thần kinh cánh tay ở trẻ em cung cấp hình ảnh có độ chi tiết cao, cho phép phát hiện, phân độ và phân loại vị trí tổn thương của các rễ thần kinh trong đám rối, từ đó giúp bác sĩ lâm sàng có thông tin để lập kế hoạch quản lý và điều trị tổn thương phù hợp.

\section{TÀI LIẸU THAM KHẢO}

1. Smith BW, Daunter AK, Yang LJ, Wilson TJ. An Update on the Management of Neonatal Brachial Plexus Palsy - Replacing Old Paradigms: A Review. JAMA Pediatr. 2018;172 (6):585 - 591.

2. Lalka A, Gralla J, Sibbel SE. Brachial Plexus Birth Injury: Epidemiology and Birth Weight Impact on Risk Factors. J Pediatr Orthop. 2020;40 (6):e460 - e465.

3. Van der Looven R, Le Roy L, Tanghe E, et al. Risk factors for neonatal brachial plexus palsy: a systematic review and meta - analysis. Dev Med Child Neurol. 2020;62 (6):673 - 683. 
4. Lagerkvist $A L$, Johansson $U$, Johansson A, Bager B, Uvebrant P. Obstetric brachial plexus palsy: a prospective, population - based study of incidence, recovery, and residual impairment at 18 months of age. Dev Med Child Neurol. 2010;52 (6):529 - 534.

5. Pondaag W, Malessy MJ, van Dijk JG, Thomeer RT. Natural history of obstetric brachial plexus palsy: a systematic review. Dev Med Child Neurol. 2004;46 (2):138 - 144.

6. Chauhan SP, Blackwell SB, Ananth CV. Neonatal brachial plexus palsy: incidence, prevalence, and temporal trends. Semin Perinatol. 2014;38 (4):210 - 218.

7. Tagliafico A, Succio G, Emanuele Neumaier $C$, et al. MR imaging of the brachial plexus: comparison between 1.5 - T and 3 - T MR imaging: preliminary experience. Skeletal Radiol. 2011;40 (6):717 - 724.

8. Lee SK, Wolfe SW. Peripheral nerve injury and repair. J Am Acad Orthop Surg. 2000;8 (4):243 - 252.

9. Chhabra A, Ahlawat S, Belzberg A, Andreseik G. Peripheral nerve injury grading simplified on MR neurography: As referenced to Seddon and Sunderland classifications. Indian J Radiol Imaging. 2014;24 (3):217 - 224.

10, Yoshikawa T, Hayashi N, Yamamoto $\mathrm{S}$, et al. Brachial plexus injury: clinical manifestations, conventional imaging findings, and the latest imaging techniques. Radiographics. 2006;26 Suppl 1:S133 - 143.

11. Gasparotti R, Ferraresi S, Pinelli L, et al. Three - dimensional MR myelography of traumatic injuries of the brachial plexus. AJNR Am J Neuroradiol. 1997;18 (9):1733 - 1742.

12. Tsai PY, Chuang TY, Cheng $\mathrm{H}, \mathrm{Wu}$ HM, Chang YC, Wang CP. Concordance and discrepancy between electrodiagnosis and magnetic resonance imaging in cervical root avulsion injuries. J Neurotrauma. 2006;23 (8):1274 - 1281.

13. Gasparotti R, Lodoli G, Meoded A, Carletti F, Garozzo D, Ferraresi S. Feasibility of diffusion tensor tractography of brachial plexus injuries at 1.5 T. Invest Radiol. 2013;48 (2):104 $-112$.

14. Hayashi N, Masumoto T, Abe O, Aoki S, Ohtomo K, Tajiri Y. Accuracy of abnormal paraspinal muscle findings on contrast enhanced MR images as indirect signs of unilateral cervical root - avulsion injury. Radiology. 2002;223 (2):397 - 402.

15. Andreisek G, Burg D, Studer A, Weishaupt D. Upper extremity peripheral neuropathies: role and impact of MR imaging on patient management. Eur Radiol. 2008;18 (9):1953 - 1961.

\section{Summary \\ MAGNETIC RESONANCE IMAGING IN CHILDREN WITH OBSTETRIC BRACHIAL PLEXUS INJURY}

Obstetric brachial plexus injury is a co mmon injury in children. The traditional method of diagnosis depends on physical examination and electromyography. Three Tesla magnetic resonance imaging ( $3 \mathrm{~T} \mathrm{MRI)}$ is a new tool for identification of lesions of the obstetric brachial plexus in children. Our goal was to assess the effectiveness of 3T MRI in diagnosis. Seventy five patients underwent $3 \mathrm{~T}$ MRI. The result showed that all of the plexus was displayed with good quality ( $3.1 \pm 0,25$ points on T1W and $3.9 \pm 0,11$ points on T2W, STIR and CISS). All roots C5, C6 were damaged, in which the predominance damage was of Sunderland degree IV and V. Roots 
C7, C8 had lower frequency of damage and mostly were of degree V. In the damaged roots, the rate of root alvusion was $34 \%$, pseudomeningoceles was $32.3 \%$, neuroma was $40,2 \%$, and diffuse edema was $94.8 \%$. In conclusion, 3 T MRI is a noninvasive diagnostic method that can be used to assess and classify lesions in obstetrical brachial plexus palsy for prognosis and treatment planning.

Keywords: Obstetric brachial plexus injury; 3T MRI, Erb's palsy. 